\title{
Control Performance of Different Bra Designs and Materials during Physical Activity
}

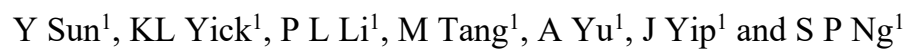 \\ ${ }^{1}$ Institute of Textiles and Clothing, The Hong Kong Polytechnic University, Hong Kong
}

\begin{abstract}
Bras give support to the breasts and prevent damage to their different components during daily activities. Previous studies have however merely focused on specific types of bras and/or shoulder straps but failed to provide specific guidelines on bra features and materials that can be used to improve the support different functions of bras. The purpose of this study is to evaluate the breast control performance of various types and designs of bra under the conditions of walking and running. Two younger women and 1 older woman (all with a bra size of $36 \mathrm{C} / 80 \mathrm{C}$ ) have participated in a wear trial to don a total of 12 different commercial bras with different design features, and a changeable bra in which 12 different variables are examined, including the materials, strap width and type of underwire. The $3 \mathrm{D}$ movement of the breasts in the various bra conditions during walking at a speed of $4 \mathrm{~km} / \mathrm{h}$ and running at $6 \mathrm{~km} / \mathrm{h}$ is recorded and then compared with the braless condition by using an 11-camera motion capture system. The percentage of change in the nipple displacement in the vertical direction relative to the clavicle displacement is used to quantify and compare the breast control performance of the bras. A significant difference $(p<0.01)$ in the ability of the bras to control movement is observed between the group of younger subjects and the mature subject (left breast: $11.49 \%$ vs. $35.42 \%$, and right breast: $18 \%$ vs. $32.47 \%$, respectively). The control performance of the bras is significantly different $(\mathrm{p}<0.01)$ during running and walking (left breast: $26.39 \%$ vs. $12.54 \%$, and right breast: $30.04 \%$ vs. $15.61 \%$, respectively). The correlation analysis showed that a small bra cup volume (length across the bra cup), taller gore, elongation of the bra strap and bra band, and rigid bra cup fabric allow good control of vertical breast displacement.
\end{abstract}

\section{Introduction}

In their natural state, breasts are likely to deform and sag under gravity due to the lack of anatomical support. Large inertial forces are exerted onto the breasts, especially during when the body moves to do daily activities or perform intensive exercise, which will cause stretching of the Cooper's ligaments in the breasts and lead to discomfort [1]. Steele [2] reported that some women can experience breast pain even with a mere $2 \mathrm{~cm}$ of breast displacement in the vertical direction. A good bra is therefore important to provide sufficient support of the breasts against gravity and control their excessive movement during daily activities [3]. To control movement of the breasts, bra performance is important and related to the design features and materials used [4]. In order to investigate the performance of a bra in preventing breast displacement during activity, objective measurements of the breast kinematics have been conducted by monitoring the three-dimensional (3D) trajectories of markers attached to certain points on a bra [5][6][7]. Starr et al. [8] compared two major types of sports bras (compression versus encapsulation bras) through a breast motion analysis. The compression sports bra caused greater vertical breast displacement in comparison to the encapsulation sports bra. Lu et al. [9] examined the material properties of sports bras and addressed the influence of type of material used in the sports bra design on the interaction between the bra and breasts. They concluded that both biaxial tensile and compression properties of bra materials should be considered in sports bra designs. Research studies have also focused on the evaluation of breast motion with different levels of bra support (high, medium, or low level of support) or bra type (everyday bra, or compression or encapsulation sports bra) [5][10]. However, the bra styles are usually limited in these studies which fail to address the large differences in bra features and their influence on controlling breast motion with different levels of activity. The purpose of this study is to therefore propose a systematic evaluation of bra features in controlling breast motion under the conditions of walking and running.

\section{Methods}

\subsection{Participants}


Two younger females (S1: 26 years old, and S2: 29 years old) and one older female (S3: 62 years old) were recruited for participation in the study. They all have a bra size of $36 \mathrm{C} / 80 \mathrm{C}$. They have not undergone any breast surgery and are not pregnant or breast feeding which may cause changes to the properties of the breast tissues or affect natural breast motion. The project was approved by the University Human Subjects Ethics Committee. Before taking part in the wear trial experiment, informed consent was received from all of the subjects.

\subsection{Bra samples}

A total of 13 bras were used for the wear trial, which included 12 commercial bras with different design features and 1 changeable bra which allows the replacement of bra components such as the materials, strap (different widths) and underwire (different types). As such, 12 different variables were examined, which provided 12 different bra conditions. The details of the bras are listed in Table 1 and shown in Figure 1.

Table 1. Details of commercial bra samples

\begin{tabular}{|c|c|c|c|c|}
\hline & 1 & 2 & 3 & 4 \\
\hline \multicolumn{5}{|l|}{ Bra style } \\
\hline $\begin{array}{l}\text { Design } \\
\text { features }\end{array}$ & $\begin{array}{ll}\text { - } & \text { Moulded foam cup } \\
\text { - } & \text { Hard underwire } \\
\text { - } & \text { No cradle } \\
\text { - } & \text { U-back } \\
\text { - } & \text { Hook and eye } \\
\text { fastener }\end{array}$ & $\begin{array}{ll}\text { - } & \text { Cut and sewn } \\
\text { elastic lace and } \\
\text { lining } \\
\text { - } \text { Hard underwire } \\
\text { - } \quad \text { Elastic cradle } \\
\text { - U-back } \\
\text { - Hook and eye } \\
\text { fastener } \\
\end{array}$ & $\begin{array}{ll}\text { - } & \text { Cut and sewn rigid } \\
\text { - } & \text { lace } \\
\text { - } & \text { Hard underwire } \\
\text { - } & \text { Straigtic cradle } \\
\text { - } & \text { Hook back } \\
& \text { fastener }\end{array}$ & $\begin{array}{ll}\text { - } & \text { Moulded foam cup } \\
\text { - } & \text { No underwire } \\
\text { - } & \text { Elastic cradle } \\
\text { - } & \text { U-back } \\
\text { - } & \text { Hook and eye } \\
\text { fastener }\end{array}$ \\
\hline & 5 & 6 & 7 & 8 \\
\hline \multicolumn{5}{|l|}{ Bra style } \\
\hline $\begin{array}{l}\text { Design } \\
\text { features }\end{array}$ & $\begin{array}{ll}\text { - } & \text { Cut and sewn foam } \\
\text { cup } \\
\text { - } & \text { Soft underwire } \\
\text { - } & \text { Elastic cradle } \\
\text { - } & \text { U-back } \\
\text { - } & \text { Hook and eye } \\
\text { fastener }\end{array}$ & $\begin{array}{ll}\text { - } & \text { Moulded foam cup } \\
\text { - } & \text { Soft underwire } \\
\text { - } & \text { One piece cradle } \\
\text { (moulded) } \\
\text { - } \\
\text { - U-back } \\
\text { Hook and eye } \\
\text { fastener }\end{array}$ & $\begin{array}{ll}\text { - } & \text { Moulded foam cup } \\
\text { - } & \text { Hard underwire } \\
\text { - } & \text { Elastic cradle } \\
\text { - } & \text { U-back } \\
\text { - } & \text { Hook and eye } \\
\text { fastener }\end{array}$ & $\begin{array}{llr}\text { - } & \text { Elastic fabric } \\
\text { inserted } & \text { with } \\
\text { moulded foam } & \text { padding } \\
\text { - } & \text { No underwire } \\
\text { - } & \text { Stretch lace cradle } \\
\text { - } & \text { No straps } \\
\text { - } & \text { No closure } \\
\end{array}$ \\
\hline & 9 & 10 & 11 & 12 \\
\hline \multicolumn{5}{|l|}{ Bra style } \\
\hline $\begin{array}{l}\text { Design } \\
\text { features }\end{array}$ & $\begin{array}{ll}\text { - } & \text { Seamless knitted } \\
\text { fabric } \\
\text { - } & \text { No underwire } \\
\text { - } & \text { Seamless cradle } \\
& \text { (knit) } \\
\text { - } & \text { U-back } \\
\text { - } & \text { No closure }\end{array}$ & $\begin{array}{ll}\text { - } & \text { Cut and sewn } \\
\text { elastic fabric } \\
\text { - } & \text { No underwire } \\
\text { - } & \text { Elastic cradle } \\
\text { - } & \text { U-back } \\
\text { - } & \text { Hook and eye } \\
\text { fastener }\end{array}$ & $\begin{array}{llr}\text { - } & \text { Elastic } & \text { fabric } \\
\text { inserted } & \text { with } \\
& \text { moulded foam } \\
& \text { padding } \\
\text { - } & \text { No underwire } \\
\text { - } & \text { Elastic cradle } \\
\text { - } & \text { Racer back } \\
\text { - } & \text { No closure } \\
\end{array}$ & $\begin{array}{l}\text { - } \text { Cut and sewn } \\
\text { elastic fabric } \\
\text { - } \quad \text { Hard underwire } \\
\text { - } \quad \text { Stretch lace cradle } \\
\text { - } \quad \text { U-back } \\
\text { - } \quad \text { Hook and eye } \\
\text { fastener }\end{array}$ \\
\hline
\end{tabular}




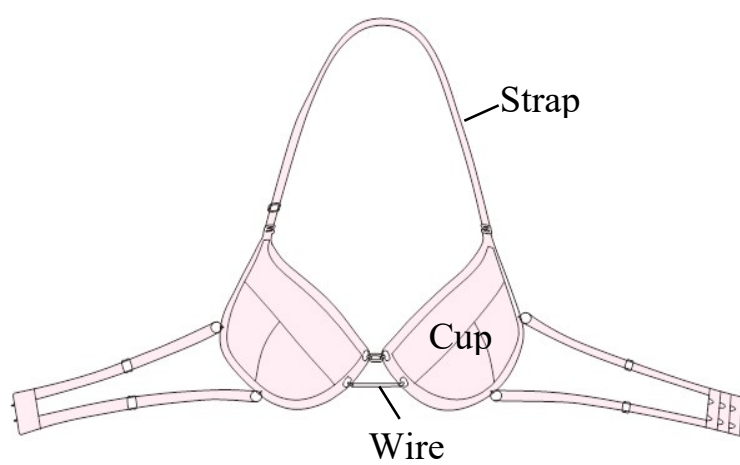

\begin{tabular}{|c|c|c|c|}
\hline $\begin{array}{c}\text { Changeable } \\
\text { bra styles }\end{array}$ & Cup & $\begin{array}{c}\text { Strap width } \\
\text { (mm) }\end{array}$ & Wire \\
\hline 21 & Moulded & 12 & 2460 (light) \\
\hline 22 & Moulded & 12 & 2860 (heavy) \\
\hline 23 & Moulded & 16 & 2460 \\
\hline 24 & Moulded & 16 & 2860 \\
\hline 25 & Woven & 12 & 2460 \\
\hline 26 & Woven & 12 & 2860 \\
\hline 27 & Woven & 16 & 2460 \\
\hline 28 & Woven & 16 & 2860 \\
\hline 29 & Knitted & 12 & 2460 \\
\hline 30 & Knitted & 12 & 2860 \\
\hline 31 & Knitted & 16 & 2460 \\
\hline 32 & Knitted & 16 & 2860 \\
\hline
\end{tabular}

Figure 1. Changeable bra sample and different bra conditions

\subsection{Motion capture experiment}

In order to examine breast motion during activity, a Vicon motion capture system with 8 Vantage cameras and 3 Vero cameras was used to record the dynamic breast displacement. The subjects underwent 3 walking trials at a rate of $4 \mathrm{~km} / \mathrm{h}$ and 3 running trials at $6 \mathrm{~km} / \mathrm{h}$ in random order on a treadmill with $0^{\circ}$ slope (braless, and wearing the 12 commercial bras and changeable bra with the 12 bra conditions). Each trial was recorded for 20 seconds with the subject standing, 60 seconds while she was walking/running and then 20 seconds with the subject standing again. Since displacement in the vertical direction contributes to most of the $3 \mathrm{D}$ dynamic movement of the breasts [11], only vertical displacement is examined in this study. The coordinates in the vertical direction ( $\mathrm{z}$ axis in the Vicon system) of the markers on the two nipple points and clavicle were extracted for further analysis.
A well-designed bra can reduce excessive breast displacement during dynamic movement. In this study, the percentage of change in the nipple displacement (PND) in the vertical direction relative to the clavicle displacement in comparison to the braless condition is used as a criterion of bra performance in controlling breast displacement. The change is calculated by using equation (1). For each bra condition, 20 cycles of stride were extracted to obtain the average value of the relative peak/valley of the nipple displacement. The Figure 2 shows the relative nipple displacement (RND) in the condition of braless and wearing bra condition, respectively.

$$
\mathrm{PND}=\frac{\mathrm{A}_{\mathrm{n}}-\mathrm{A}_{\mathrm{b}}}{\mathrm{A}_{n}} \times 100 \%
$$

where $A_{n}$ represents the relative nipple displacement (RND) in the braless condition, and $A_{b}$ is the RND in the bra wearing condition.

\section{Results and discussion}

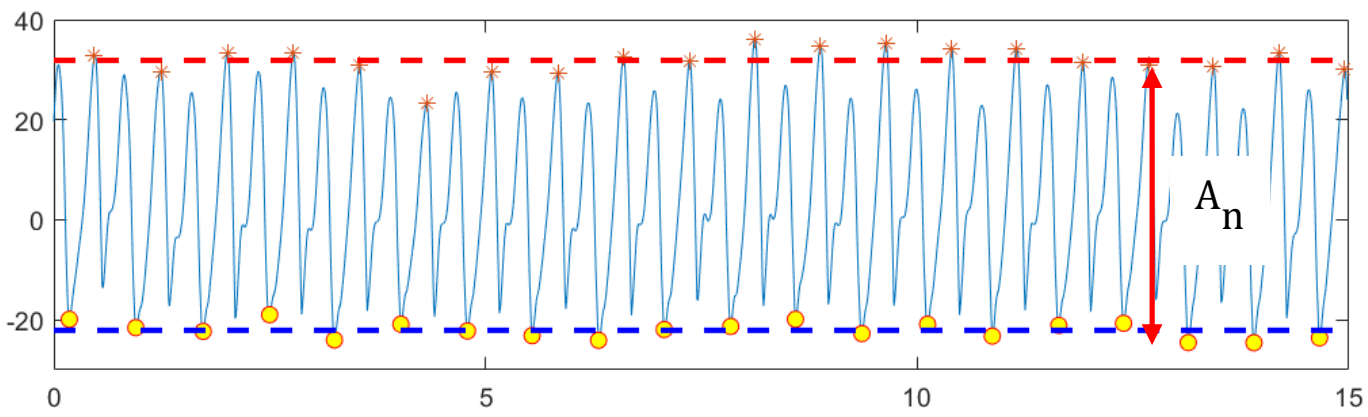

(a) Braless condition 


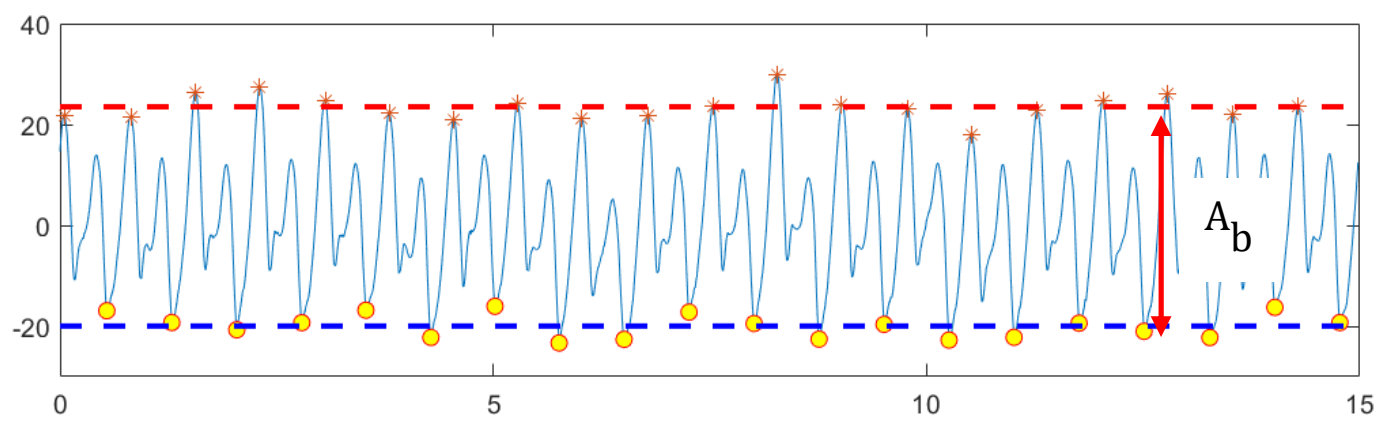

(b) Wearing bra condition

Figure 2. Relative nipple displacement $(\mathrm{cm})$ in the condition of braless and wearing bra condition

The overall RND in the vertical direction obtained from Commercial Bras 1 to 12 and Changeable Bra Conditions 21 to 32 as compared to the braless (nude) state during running and walking is presented in Figures 3(a) and 3(b), respectively. The results indicate that the older subject (S3) shows a lower RND and higher PND than the younger subjects (S1 and S2) in all of the bra conditions during running and walking. A significant difference $(\mathrm{p}<0.01)$ of the ability of the bra to control movement can be observed between the group of younger subjects (PND of left breast: 11.49\%,

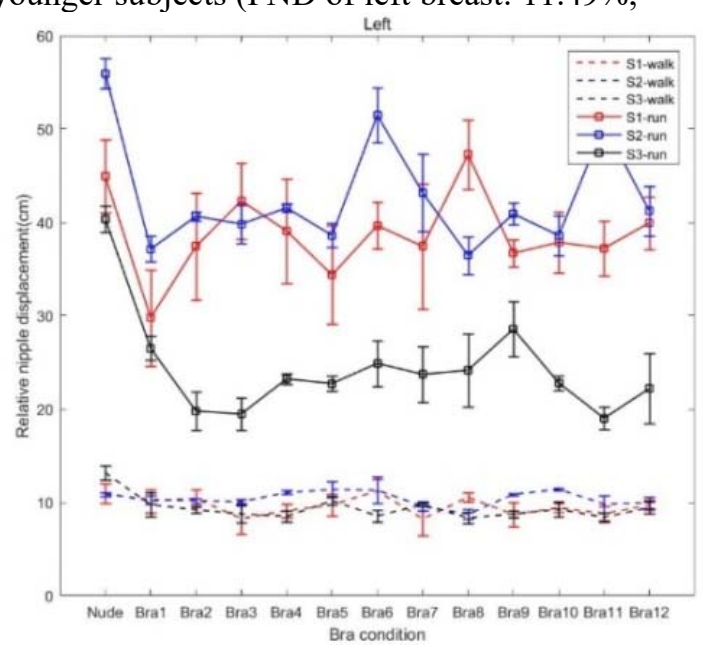

and PND of right breast: 18\%) and older subject (PND of left breast: $35.42 \%$, and PND of right breast: $32.47 \%$ ). However, no significant difference can be found between the two younger subjects themselves $(\mathrm{p}>0.01)$. The control performance of all of the bras when donned by the subjects showed a significant difference $(\mathrm{p}<0.01)$ between running and walking (PND of left breast: $26.39 \%$ when running vs. $12.54 \%$ when walking, and PND of right breast: $30.04 \%$ when running vs. $15.61 \%$ when walking).

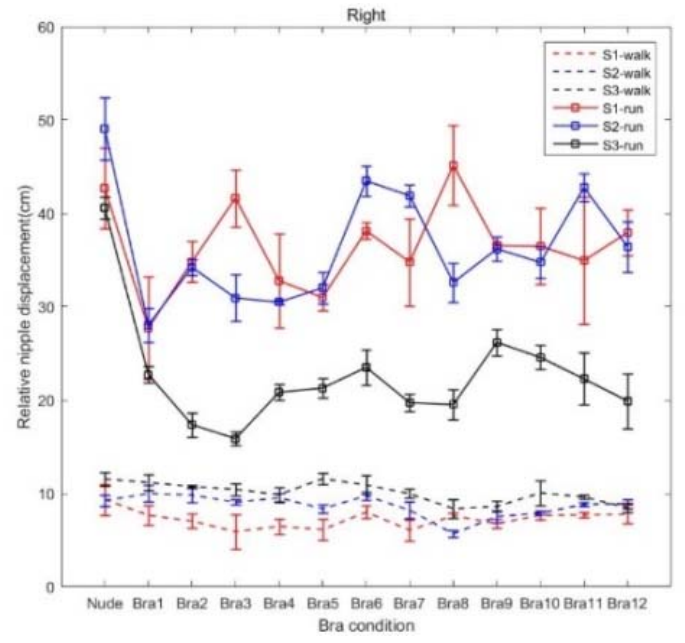

Figure 3(a). RND in vertical direction: Commercial bras and braless condition
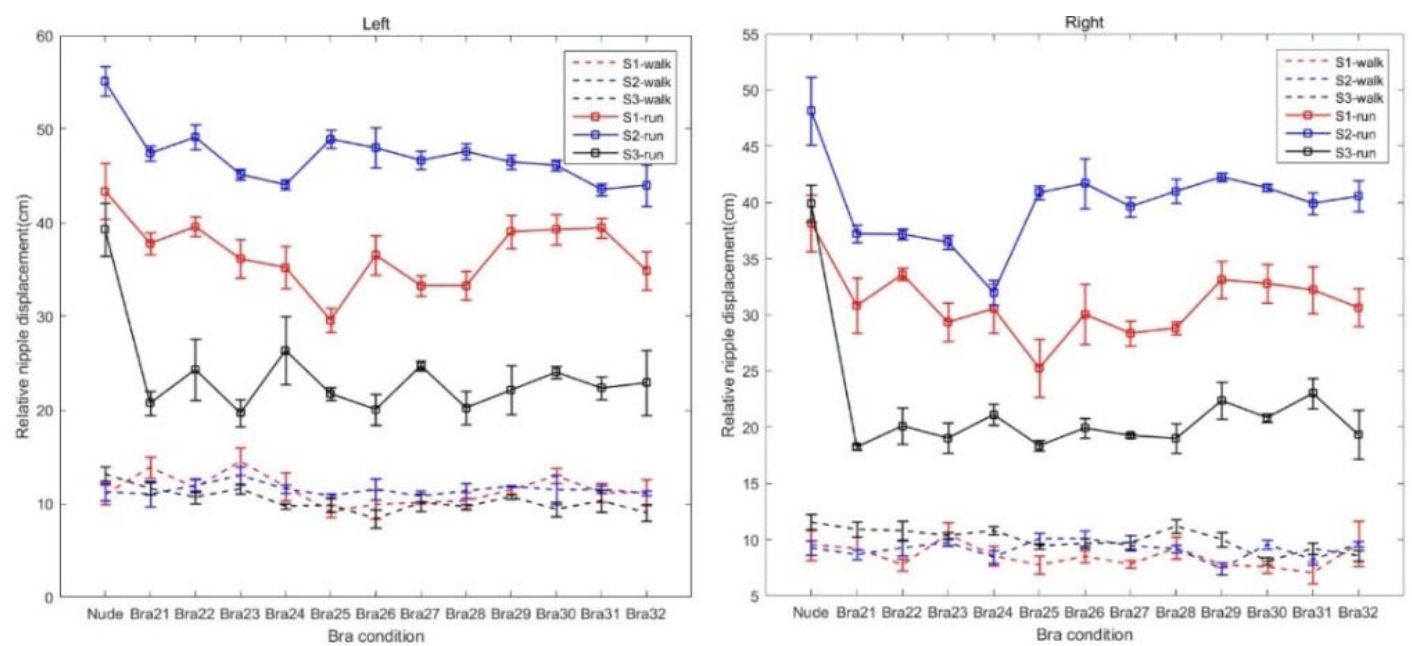

Figure 3(b). RND in vertical direction: Changeable bra and braless conditions 
In order to evaluate the influence of the bra features on the control performance of the bra during walking and running, 11 measurements were taken for the commercial bras (including length of the neckline, length across the bra cup, height of the bra cup, length from the top to bottom of the gore, height of the gore, length of the wire channel, side seam, bra band, and length and width of the shoulder strap) and 6 material tests were carried out (including the elongation of the bra band, modulus and thickness of the shoulder strap, and thickness of the cup and its modulus in the course and wale directions) for the correlation analysis. No relationship was found between the bra measurements and percentage of control of breast displacement in the running condition. However, a negative relationship was found during walking for the measurement of the length across the bra cup (left breast: $r=-0.380$, $\mathrm{p}=0.038$, and right breast: $\mathrm{r}=-0.464, \mathrm{p}=0.01$ ) and the PND. In addition, the height of the gore (left breast: $r=-$ $0.330, \mathrm{p}=0.049$, and right breast: $\mathrm{r}=-0.352, \mathrm{p}=0.035$ ) and elongation of the shoulder strap (left breast: $r=-$ $0.442, p=0.01$, and right breast: $r=-0.368, p=0.035$ ) have a negative relationship with the RND. A smaller distance across the bra cup, taller gore and increased elongation of the bra strap could possibly enhance the control performance of a bra. The elongation of the bra band has a negative relationship with the RND (left breast: $\mathrm{r}=-0.404, \mathrm{p}=0.015$ ) and positive relationship with the PND (left breast: $r=0.426, p=0.01$ ), which shows that increased elongation of the bra band can enhance control over breast motion.

As for the changeable bras, the effects of the 12 variables, which include the bra cup materials, width of the shoulder strap and type of underwire on the control performance, were investigated. The correlation analysis revealed that there is no relationship between any of the variables and control performance in the running condition. However, the Young's modulus of the changeable bra cup material has a positive relationship $(\mathrm{r}=0.343, \mathrm{p}=0.041)$ with the control performance of the left breast during walking. A T-test and one-way analysis of variance (ANOVA) were conducted to determine whether the RND and PND for the different bra conditions would have significant differences between/ among the different variables. It was found that there is no significant difference between the different strap widths and types of underwire (T-test, $\mathrm{p}>0.05$ ). However, the results for the bra cup material showed a significant difference between the knitted and woven materials $(p<0.01)$ in controlling the displacement of the left breast.

\section{Conclusion}

This study evaluates the control performance of various types and designs of bras during different activities. The PND in terms of the vertical displacement of the breasts under different bra conditions is determined and the results indicate that mature women who wear a bra can better control the displacement of their breasts in the vertical direction. During walking, the correlation analysis shows that a small cup volume (smaller distance across the length of the bra cup), taller gore, increased elongation of the bra strap \& band and the use of rigid fabric for the bra cup can enhance the control of vertical breast displacement. However, there are some limitations in this study that prevent the generalization of the results. The sample size is small and the different bra features of the changeable bra do not shown any significant differences during running. In future studies, it is recommended that a larger sample size is used which could provide more data to carry out a statistical analysis.

\section{Acknowledgment}

We acknowledge financial support from ITF grant for project ITS/276/18.

\section{Reference}

1. Yu W and Zhou J 2016 Sports bras and breast kinetics Advances in women's intimate apparel technology (UK: Woodhead Publishing) pp 135146

2. Steele J R 2013 The biomechanics of better bras: improving support and comfort during exercise ISBS-Conference Proceedings Archive

3. Liu K, Zhang L, Zhu C, Zhao X, Lu W, Li M and Wang J 2019 An analysis of influence factors of sports bra comfort evaluation based on different sizes J. Text I. 110 1792-1799

4. Lawson L J and Lorentzen D 1990 Selected Sports Bras: Comparisons of Comfort and Support Text. Res. J. 8 55-60

5. White J L, Scurr J C and Smith N A 2009 The effect of breast support on kinetics during overground running performance Ergonomics 52 492-498

6. Zhou J, Yu W and Ng S P 2013 Identifying effective design features of commercial sports bras Text. Res. J. 83 1500-1513

7. Zhou J, Yu W and Ng S P 2012 Studies of threedimensional trajectories of breast movement for better bra design Text. Res. J. 82 242-254

8. Starr C, Branson D, Shehab R, Farr C, Ownbey S and Swinney J 2005 Biomechanical analysis of a prototype sports bra J. Text. Appar. Technol. Manag. 4 1-14

9. Lu M, Qiu J, Wang G and Dai X 2016 Mechanical analysis of breast-bra interaction for sports bra design Mater. Today Commun. 6 28-36 
10. Scurr J C, White J L and Hedger W 2011 Supported and unsupported breast displacement in three dimensions across treadmill activity levels $J$. Sports Sci. 29 55-61

11. Mason B R, Page K A and Fallon K 1999 An analysis of movement and discomfort of the female breast during exercise and the effects of breast support in three cases J Sci Med Sport 2 134-144 